\title{
Methods of In Situ Assessment of Infiltration Rate Reduction in Groundwater Recharge Basins
}

\author{
Felix Barquero * (D), Thomas Fichtner and Catalin Stefan $\mathbb{D}$ \\ Research Group INOWAS, Department of Hydrosciences, Technische Universität Dresden, \\ 01069 Dresden, Germany; thomas.fichtner@tu-dresden.de (T.F.); catalin.stefan@tu-dresden.de (C.S.) \\ * Correspondence: felix.barquero@mailbox.tu-dresden.de; Tel.: +49-351-463-441-68
}

Received: 6 March 2019; Accepted: 11 April 2019; Published: 16 April 2019

\begin{abstract}
As an alternative to the use of tracers, easy-to-measure soil moisture dynamic parameters (e.g., water content) provide in situ estimates of the infiltration rate reduction state of a soil medium. For instance, managed aquifer recharge operations control the hydraulic state of their infiltration basins by measuring the infiltrated volume under constant head conditions. Instantaneous profile measurement systems can be used to manage the basins by determining the reduction of the infiltration rate over time. This study combines the empirical methods of Libardi, the self-developed water content and root mean square difference-based procedures and the trigger time method, to get a similar reproduction of tracer results from river water spreading basins. The methods based on water content showed a good fitting in comparison to the results obtained with the tracer experiment and represent a promising source for detecting changes in the flow impedance during infiltration events.
\end{abstract}

Keywords: infiltration rate; hydraulic properties; tracer; groundwater recharge; vadose zone

\section{Introduction}

Managed aquifer recharge (MAR) has recieved increased attention in recent decades as a potential measure to alleviate and mitigate problems of water allocation, saltwater intrusion, and replenishment of over-exploited aquifers; both to reduce evaporative losses and to improve water quality [1]. One of the main methods of MAR is the use of surface spreading basins, which has an added benefit of using the vadose zone as a filter to trap and break down organic and inorganic compounds before water reaches the aquifer [2], as well as being a cost-effective measure compared to alternatives $[3,4]$. Given that this concept is gaining more relevance as a mitigation approach against climate change, further investigation of the processes involving MAR has to be performed in order to maximise its efficiency [5]. When working with surface water or reclaimed water, some MAR plants have begun to introduce hydraulic loading cycles (HLC) or flooding and drying cycles in their infiltration schedules. This change consists in a period of water application, followed by a temporary pause of infiltration to allow for the recovery of oxygen levels in the upper section of the infiltration basin, which induces the maximum decomposition rate of organic matter, especially for nitrification processes [6-8]. An example of a common HLC is one day of flooding followed by a drying period of two or three days, at which point the cycle begins again with a new $24 \mathrm{~h}$ period of flooding [9]. Nevertheless, there are also recharge sites where these cycles are not introduced, since the quality of the recharged water does not require further treatment through the vadose zone, and the aim of the project is mainly focussed on the hydraulic restoration of the groundwater level [10]. This type of infiltration is refered to in this study as 'continuous infiltration'.

For MAR sites, it is critical to monitor the hydraulic conductivity $(\mathrm{K})$, which is one of the main properties that indicates the capacity of a the soil to permit water infiltration or percolation. The determination of $\mathrm{K}$ in an unsaturated soil is necessary for the processing and understanding 
of soil-water transport processes such as mass transfer, heat transfer, and infiltration/runoff [11,12]. Evaluation of in situ K represents a challenge, especially in non-disturbed conditions, and many methods have been designed to measure $\mathrm{K}$ in the field; such as single/double ring infiltrometer, Auger-Hole method tension infiltrometer, and constant head well permeameter [11,13-15]. Nevertheless, all of these approaches determine point values for the hydraulic properties of interest. Additionally, all of these techniques are invasive, as they require some alterations of the soil in the experimental setup, which will influence either the water content/matric potential conditions or the compaction of the soil. This effect can be highly relevant with regards to the study of $K$ changes driven by the clogging of pores, because the implementation of these invasive methods represents a modification of the initial boundary conditions in an investigation scheme with repeated infiltration cycles, as is the case in MAR spreading basins.

The hydraulic conductivity of near-surface soils plays a key role in surface spreading operations, since it is the main parameter that controls the capacity of the site to recharge the aquifer. For the investigation of factors driving the reduction of infiltration rate caused by clogging (decrease of $\mathrm{K}$ ) in infiltration basins, soil samples are typically taken while the infiltration basin is empty. Invasive soil sampling techniques affect the starting conditions for following infiltration cycles. Similarly, instruments such as constant head permeameters influence the initial boundary conditions (the medium would remain with a higher water content) for the next infiltration cycle. Thus, these methods are not appropriate for monitoring the development of clogging in the MAR basins under specific hydraulic scenarios.

To overcome these challenges, systems of instantaneous profile measurements (IPM) have been developed, which can estimate hydraulic properties of the soil using long-term time series data [16]. IPM is a system of supplying measurements of particular parameters (e.g., water content, tension, temperature, electrical conductivity) in time at different depths [17]. IPM enables the calculation of water front movement, and therefore drying behavior at different depths. Reichardt [18] addressed the prediction of hydraulic conditions of the soil without disturbing the experimental setup or influencing the hydraulic changes using IPM and Libardi's equation.

The objective of this study is to compare different established and new methods to calculate the reduction of the infiltration rate over time based on IPM data. These methods were selected according to their capacities to track changes in the infiltration rate (due to clogging of the basin floor) over time, without influencing the conditions of the experimental setup for the subsequent infiltration cycles. The water content data of two MAR infiltration unit experiments (field- and lab scale) were selected as representative input data for tracking the decrease of the hydraulic conductivity over time after the infiltration of river water.

Implementing the developed techniques in recharge facilities would bring more knowledge regarding the effects on water and its organic as well as inorganic components during the flooding cycles. This should maximise the time in which the infiltration basin can be operated and programmed accurately the best timing for its maintenance. The suggested methods are not meant to substitute any other already existing analytical or numerical tool. They are employed in order to foster and complement the knowledge of the involved processes.

\section{Materials and Methods}

The infiltration experiments (See Figure 1) were run in a field scale infiltration unit $(4.5 \mathrm{~m} \times$ $3.0 \mathrm{~m} \times 1.0 \mathrm{~m})$ and a lab scale infiltration unit $(1.5 \mathrm{~m} \times 1.0 \mathrm{~m} \times 1.0 \mathrm{~m})$; both filled with a sandy soil $\left(\mathrm{Ks} \approx 6 \times 10^{-5} \mathrm{~m} / \mathrm{s}\right)$. The observation points are distributed within two layers at $0.28 \mathrm{~m}$ and $0.68 \mathrm{~m}$ depth. The lab scale experiment features an electronic scale in the outflow to control the percolation volumes, whereas in the fields scale, the lower boundary of the infiltration unit is directly connected with the unsaturated zone of the site. Infiltrated water was from the Elbe river and was mixed with sodium chloride $(\mathrm{NaCl}$ ) for tracer experiments. River water (DOC $\approx 5 \mathrm{mg} / \mathrm{L}$; TSS $\approx 20 \mathrm{mg} / \mathrm{L}$ ) was pumped into the infiltration basins with an annual hydraulic loading rate of $300 \mathrm{~m} / \mathrm{a}$ under wet:dry 
cycles of 1:3 (24 h infiltration followed by $72 \mathrm{~h}$ dry period). This designed hydraulic loading rate represents the recharge of a $300 \mathrm{~m}$ high water column with an area of $1 \mathrm{~m}^{2}$ within one year. In total, nine infiltration cycles, which were equivalent to a total specific volume of nearly $29,000 \mathrm{~L} / \mathrm{m}^{2}$, were run. Tracer experiments were performed which introduced $\mathrm{NaCl}$ at a concentration of $1 \mathrm{~g} / \mathrm{L}$ into the river water in the first six hours of each infiltration cycle, to determine the time for solute transport by way of a installed monitoring sensor, located $28 \mathrm{~cm}$ below the flooding-basin floor. The frequency domain reflectometry (FDR) sensor measures volumetric water content (vol\%), electrical conductivity $(\mathrm{mS} / \mathrm{cm})$, and temperature $\left({ }^{\circ} \mathrm{C}\right)$ at two minutes intervals. Further details of the infiltration setup and description of the measuring sensors are presented by Fichtner et al. [19].

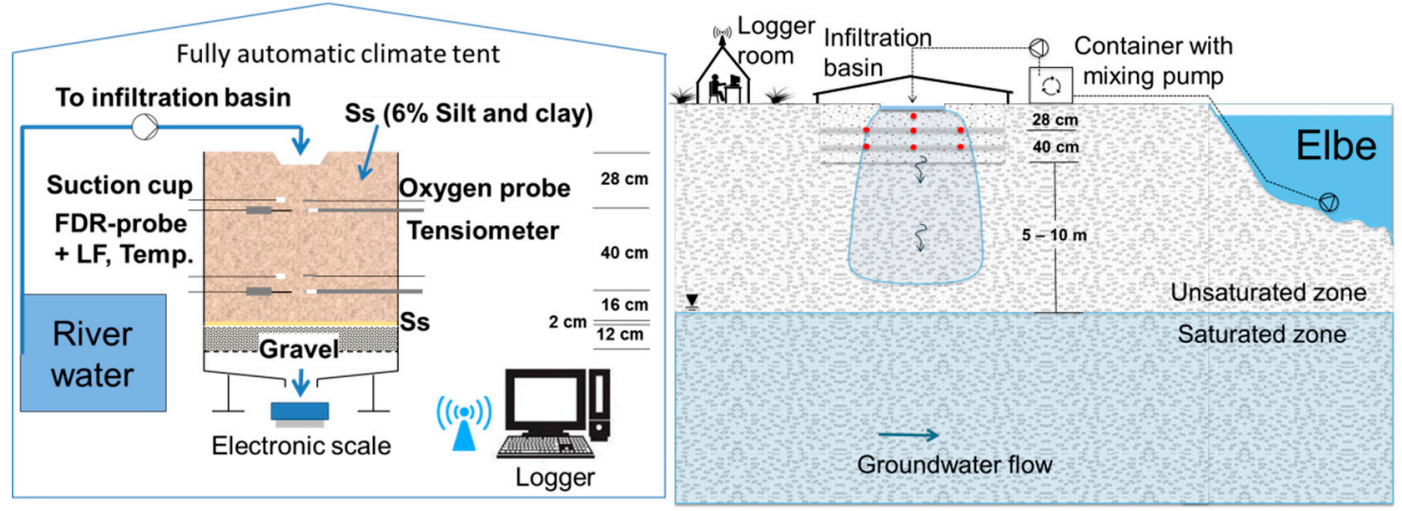

(a)

(b)

Figure 1. Experimental set-up of infiltration laboratory scale unit (a) and infiltration field scale unit (b). Both units are filled with a sandy soil $\left(\mathrm{Ks} \approx 6 \times 10^{-5} \mathrm{~m} / \mathrm{s}\right)$ and are equiped with a sensor array measuring water content, matric potential, temperature, oxygen saturation and electrical conductivity [19].

\subsection{Tracer Method}

Tracers are substances that can maintain a flow pattern similar to that of water, and are a common method for assessing changes in the hydraulic properties of a medium, especially in laboratory experiments [20,21]. Tracers should have conservative behaviour, low toxicity, and a high accuracy for analysis [22]. The advantage of adding a tracer to the infiltration solution is that they are easily traceable by using substances such as $\mathrm{NaCl}$ to determine groundwater flow, or to study leakage from rivers or sewage pipes in the saturated and unsaturated zone [23-28]. Electrical conductivity is monitored over time, which fluctuates in proportion to the concentration of salt [29]. Normally, the tracer solution is added from the start of the infiltration event, and the conductivity peak is reached in a couple of hours (depending on the depth of the sensor). The linear flow velocity is calculated by monitoring the electrical conductivity from the beginning of the infiltration cycle until the sensor at a determined depth reaches the maximum measured stage. The fraction of depth over time give the linear velocity and this value represents the standard baseline state for the wet cycle. However, sometimes the development of the infiltration capacity of the basin also requires ongoing infiltration cycles, for instance in longer infiltration periods ( $>3$ days). In this case, tracer experiments might underestimate infiltration rates due to two main factors: (1) the higher amount of voids that are filled already with water causing a different distribution of the flow paths; and (2) the dilution of the tracer in the ponded water above the infiltration basin floor.

The normalized linear velocity, expressed as $\mathrm{v}_{50} / \mathrm{v}_{50 \mathrm{o}}$ (fraction of linear velocity based on time $t_{50}$ over the initial linear velocity in the first infiltration cycle) in Equation (1), is calculated with the time it takes to reach the half of the maximum rise of electrical conductivity $\left(t_{50}\right)$ at the depth to the sensor (z) [30]. The monitored changes of $\mathrm{v}_{50} / \mathrm{v}_{50 \mathrm{o}}$ in the infiltration experiment can be interpreted as the reduction of the infiltration rate of the medium.

$$
\mathrm{v}_{50} / \mathrm{v}_{50 \mathrm{o}}=\frac{\mathrm{z}}{\mathrm{t}_{50}} / \mathrm{v}_{50 \mathrm{o}} \text {. }
$$




\subsection{Libardi Method}

Taking the basics of the Richards and the Darcy-Buckingham equation [31-33], Hillel [34] set a finite difference based analytical model to calculate the hydraulic conductivity using water content $(\theta)$ changes in flooding or draining systems. Therefore, $\theta$ was smoothed with time $t$ in a semi-log model substracting it to the initial water content $\left(\theta_{0}\right)$ :

$$
\theta_{\mathrm{o}}-\theta=\mathrm{A}_{\mathrm{L}} \ln (\mathrm{t})+\mathrm{B}_{\mathrm{L}}
$$

In order to define the fitting parameters, $A_{L}$ and $B_{L}$ at depth $L$ (Figure 2), by integrating the Richard's equation from soil surface $(\mathrm{z}=0)$ down to depth $\mathrm{z}=\mathrm{L}$, the hydraulic conductivity can be calculated (see Equation (3)). $A_{L}$ is represented by the inverse of the slope $\gamma$, whereas $B_{L}$ is the multiplication of $A_{L}$ with the natural logarithm of the fraction of slope $\gamma$ times initial hydraulic conductivity (Ko) over parameter a times depth z.

$$
\mathrm{K}(\theta)_{L}=\int_{0}^{\mathrm{L}} \frac{\partial \theta}{\partial \mathrm{t}} \mathrm{dz} /\left(\frac{\partial \mathrm{H}}{\partial \mathrm{z}}\right)_{\mathrm{L}}
$$

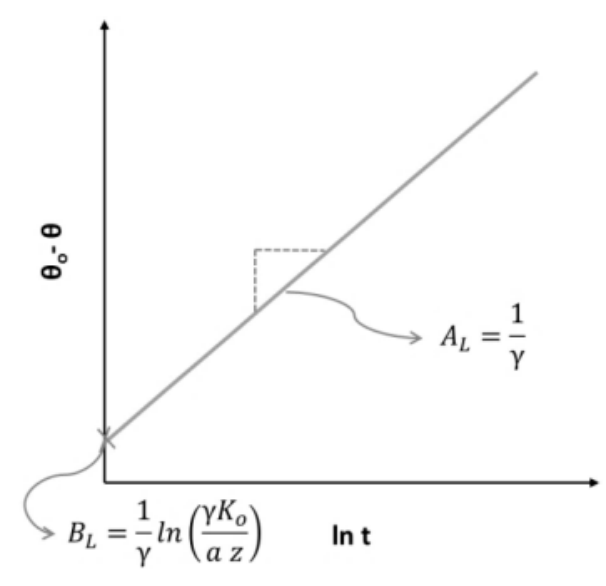

Figure 2. Smoothed semi-log model designed by Hillel and Libardi [34] for the empirical determination of the hydraulic conductivity.

From the smoothed semi-log model (Equation (2)) Hillel used finite differences for depth $\mathrm{z}$ and approximated the integral in $n$ measurements until depth $L$ and $\Delta z$ intervals in Equation (3) to:

$$
\mathrm{q}=\int_{0}^{\mathrm{L}} \frac{\partial \theta}{\partial \mathrm{t}} \mathrm{dz} \cong-\sum_{\mathrm{i}=1}^{\mathrm{n}} \frac{\mathrm{A}_{\mathrm{L}}}{\mathrm{t}} \Delta \mathrm{z} .
$$

The matric potential gradient $\left(\frac{\partial \mathrm{H}}{\partial \mathrm{z}}\right)_{\mathrm{L}}$ should be measured with tensiometers or be assumed to be unity (valid for short $\Delta \mathrm{t}$ ). Nevertheless, the finite difference can create a great gap after $\mathrm{n}$ measurements.

Libardi [35] followed the Hillel's concept and developed an empirical equation without the need of integration (Equation (5)):

$$
\mathrm{K}(\theta)=\mathrm{K}_{\mathrm{o}} \mathrm{e}^{-\gamma\left(\theta_{\mathrm{o}}-\theta\right)},
$$

where $K(\theta)$ is the water content dependent hydraulic conductivity $(\mathrm{m} / \mathrm{s}), \mathrm{K}_{\mathrm{o}}$ and $\theta_{\mathrm{o}}$ are the initial values of hydraulic conductivity and water content, respectively. For the determination of the fitting parameter $\gamma\left[\frac{1}{\gamma}\right]$ and $\mathrm{K}_{\mathrm{o}}\left[\frac{\mathrm{za}}{\gamma} \mathrm{e}^{\gamma \mathrm{B}_{\mathrm{L}}}\right]$, the linear semi $\log$ model expressed before (See Figure 2) was upgraded to:

$$
\theta_{\mathrm{o}}-\theta=\frac{1}{\gamma} \ln (\mathrm{t})+\frac{1}{\gamma} \ln \left(\frac{\gamma \mathrm{K}_{\mathrm{o}}}{\mathrm{a} \mathrm{z}}\right)
$$


Sisson [36] further simplified the equation by assuming a homogenous soil setting the parameter $\mathrm{a}=1$, which represents the same change of water content at any depth. The Libardi method features in contrast to normal tracer breakthrough curves, the calculation of an absolute value for hydraulic conductivity and not only the linear velocity.

\subsection{Root Mean Square Method}

The root mean square displacement ( $\left.D_{\text {RMS }}\right)$ was selected as an indicator of hydraulic properties variations of the soil using the data of water content from the IPM system during the infiltration phase. The $\mathrm{D}_{\mathrm{RMS}}$ is able to define the deviation distribution of the whole time series in one representative value [37]. The $D_{\text {RMS }}$ values cannot give an absolute rate of infiltration capacity reduction, but its factor of reduction can be used to infer it.

The first infiltration cycle was set as a reference. The $D_{\text {RMS }}$ is calculated between the i-th infiltration cycle $(i=1,2, \ldots, 9)$ and the first infiltration cycle in the time step $t_{x}$ like it is represented in Equation (7). This gives an approach of how much the averaged water content of each cycle changed in comparison to the initial state.

$$
\mathrm{D}_{\mathrm{RMS}}=\frac{\sum\left(\mathrm{WC}_{\text {cycle } i, \mathrm{t}_{\mathrm{x}}}-\mathrm{WC}_{\text {cycle o, } \mathrm{t}_{\mathrm{x}}}\right)^{2}}{\mathrm{n}} .
$$

In order to render this method analogous to the tracer curve, a model was developed. A quadratic regression analysis was done between the values obtained from the tracer experiments and the $D_{\text {RMS }}$ from Equation (7).

$$
\text { Tracer }_{i}=a+b \times\left[D_{\text {RMS }}\right]+c \times\left[D_{\text {RMS i }}\right]^{2} .
$$

where Tracer $_{i}$ is the calculated infiltration capacity reduction in the $i$-th infiltration cycle $(i=1,2, \ldots, 9)$ according to the tracer experiment; $D_{R M S} i$ is the calculated $D_{R M S}$ value (\%) of the $i$-th infiltration cycle; and $\mathrm{a}, \mathrm{b}$ and $\mathrm{c}$ are fitting parameters of the linear regression model. Once the model was determined the values from Equation (8) could be inserted and compared with the tracer curve data.

\subsection{Water Content Method}

The water content method is similar to the $\mathrm{D}_{\mathrm{RMS}}$ method, varying only in that instead of calculating the root mean square difference, the average water content of each infiltration cycle is calculated. Thus the infiltration time parameter of each infiltration cycle loses relevance. Similar to the previous method, a linear regression model was built and determined with the obtained data (Equation (9)).

$$
\text { Tracer }_{i}=\mathrm{a}+\mathrm{b} \times\left[\frac{\sum \mathrm{WC}_{\mathrm{i}}}{\mathrm{n}_{\mathrm{i}}}\right]+c \times\left[\frac{\sum \mathrm{WC}_{\mathrm{i}}}{\mathrm{n}_{\mathrm{i}}}\right]^{2}
$$

where Tracer $_{i}$ is the calculated infiltration capacity reduction in the $i$-th infiltration cycle $(i=1,2, \ldots, 9)$ according to the tracer experiment; $\frac{\sum W C_{i}}{n_{i}}$ is the averaged water content value (\%) of the i-th infiltration cycle; $n_{i}$ is the amount of measured data in the $i$-th infiltration cycle; and $a, b$ and $c$ are fitting parameters of the linear regression model. This model was used afterwards to be compared to the tracer curve.

\subsection{Sensor Trigger Time Method}

There are also other potential basic indicators that can be used to determine the reduction of the infiltration capacity of the medium. For example the "trigger time" that it takes for the sensor to register the first rise of the water content/tension gives a signal on the delay of the infiltration plume. This method is based more on the advection and dispersion properties of the medium, ignoring diffusion effects. A third linear regression model (Equation (10)) was built to correlate the tracer curve with the information obtained from the trigger time method.

$$
\text { Tracer }_{\mathrm{i}}=\mathrm{a}+\mathrm{b} \times\left[\mathrm{TT}_{\mathrm{i}}\right]+\mathrm{c} \times\left[\mathrm{TT}_{\mathrm{i}}\right]^{2},
$$


where Tracer $_{i}$ is the calculated infiltration capacity reduction in the $i$-th infiltration cycle $(i=1,2, \ldots, 9)$ according to the tracer experiment; $\mathrm{TT}_{\mathrm{i}}$ is the trigger time ( $\mathrm{min}$ ) of the $\mathrm{i}$-th infiltration cycle, where the water content started to rise and $\mathrm{a}, \mathrm{b}$ and $\mathrm{c}$ are fitting parameters of the linear regression model. Just as with the other models, this model was analyzed by using the tracer curve.

\section{Results and Discussion}

\subsection{Tracer Method}

The set of $t_{50}$ of each infiltration cycle against the infiltration time is shown in Figure 3, which provides an indication of the infiltration rate reduction. Additionaly, the maximum infiltration rate reduction can be identified, which is important information for MAR plant managers for deciding when a maintenance action is required. The data obtained from the tracer test is used as a reference to analyze the fit of the alternative methods and their capacity to track changes of the hydraulic conductivity.
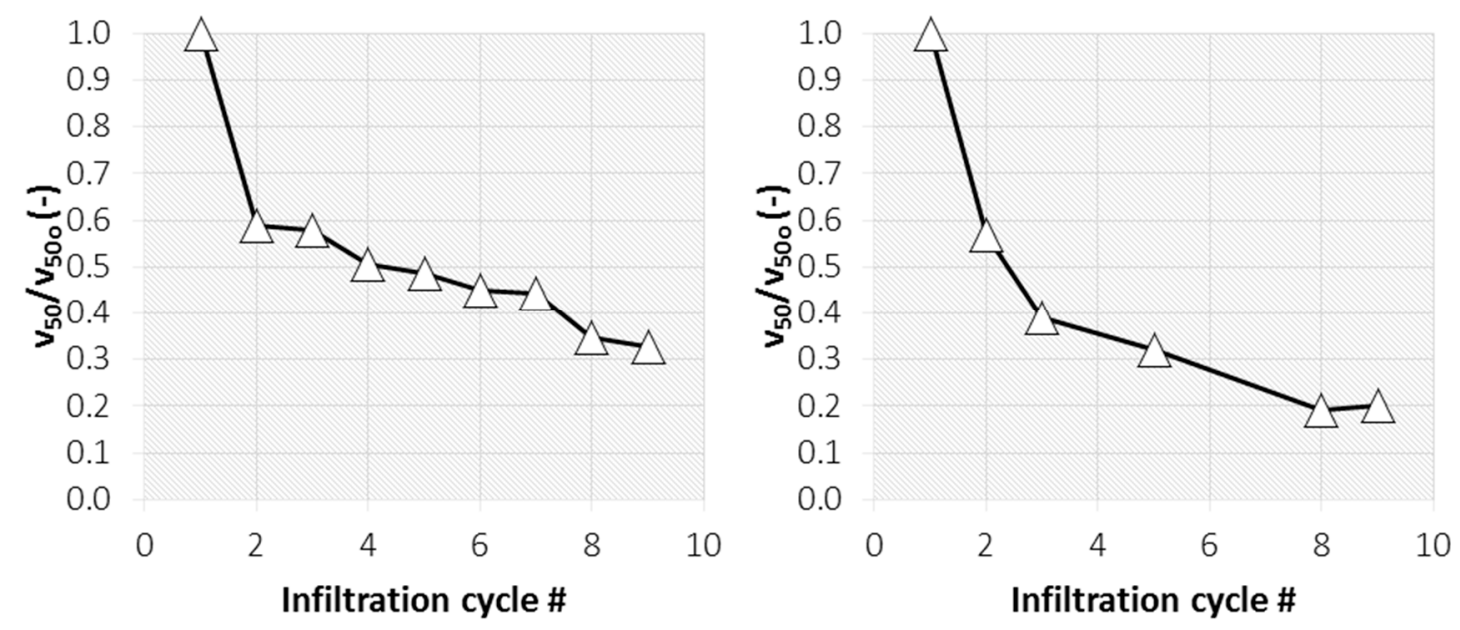

Figure 3. Infiltration rate curve determined by tracer experiments in (right) field scale and (left) lab scale. Infiltration modus: $24 \mathrm{~h}$ infiltration/72 h dry period.

\subsection{Libardi Method}

Since the Libardi equation needs a change in water content, the time series at the end of each infiltration pumping period was selected. This was selected as more appropiate than the beginning of the infiltration cycle, as the maximum water content is reached relatively fast (within 6-10 minutes) with the programmed basin pumping rate $(2.7 \mathrm{~L} / \mathrm{min}$ in field and $0.9 \mathrm{~L} / \mathrm{min}$ in lab), and this would lead to only a small amount of measurements to apply the analysis. Thus, $\theta_{\mathrm{o}}$ was set as the water content value when the drying process starts (a much slower process under gravitational forces) and $\theta$ is the water content in the time $t_{i}$, which is represented in the abscissa of the smoothing model in Figure 2 as $\ln (\mathrm{t})$. Parameter $\mathrm{A}_{\mathrm{L}}$ and $\mathrm{B}_{\mathrm{L}}$ are represented as the slope and ordinate intercept, respectively (See Figure 2).

The starting conditions of the drying process have lower water content for increasing number of cycles, and its decrease is less steeper in relation to the subsequent drying cycles (See Figure 4). After the $72 \mathrm{~h}$ dry period the difference between the cycles is minimal ( 1\%). The main difference of the water content conditions can be observed in the first 70 min of draining. 


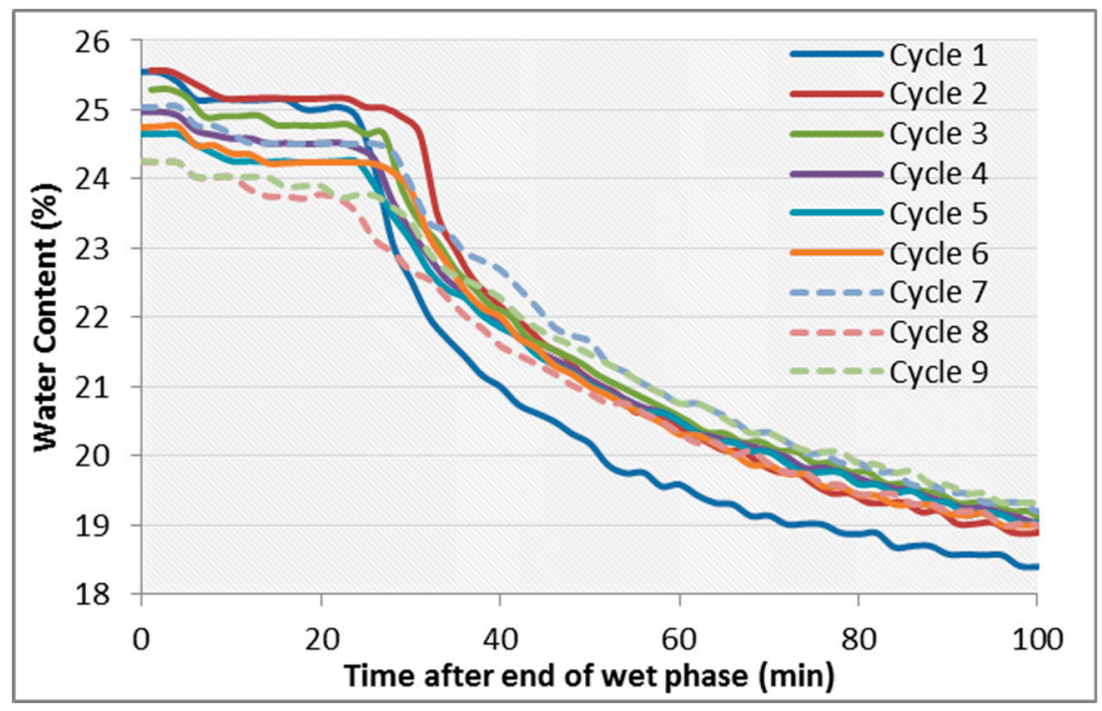

Figure 4. Water content decrease during the drying cycles in the first $100 \mathrm{~min}$ in field experiment. Infiltration modus: $24 \mathrm{~h}$ infiltration/72 h dry period.

Applying Equation (5) to the data series enables the calculation of the infiltration reduction curve (Figure 5), which represents the state of the hydraulic conductivity using the data of the drying behavior of the medium. By comparison, the Libardi method shows an overestimation of the infiltration capacity reduction. Nevertheless, the trend of the changing conditions is similar in both curves. The linear regression root mean square error (RMSE) of both Libardi curves (lab and field scale) in respect to the tracer curve are 0.40 and 0.55 for the field and lab schemes, respectively.
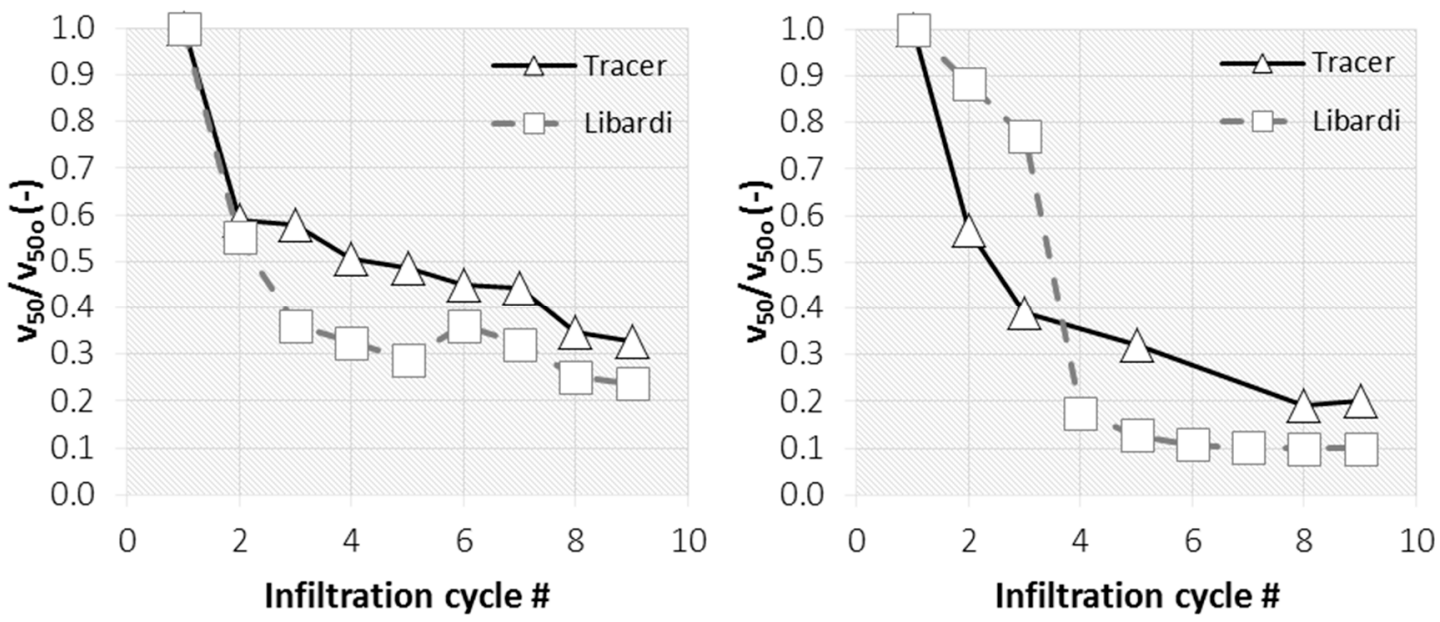

Figure 5. Infiltration capacity curve comparison between Libardi method and Tracer curve in (left) field scale and (right) lab scale. Infiltration modus: $24 \mathrm{~h}$ infiltration/72 $\mathrm{h}$ dry period.

This method takes its source of data from the drying phase of each cycle ( $72 \mathrm{~h}$ data series) and is dependant on the ponded water head in the basin at the end of the infiltration. The higher the water level is above the basin floor, the longer it will take until the sensor receives a steep reduction of the water content. Since the water head change was faster at the beginning (smaller infiltration area), a faster change in the Libardi hydraulic conductivity estimation was obtained. The clogging layer (biofilm) that develops on the surface of the infiltration basin enacts a bigger influence in drying conditions than in wetting events and this leads to higher rates of infiltration rate-reduction using Libardi calculations than tracer methodology. 


\subsection{Root Mean Square Method}

Similar to dry cycles, when overlapping the wet regime cycles, the water content decreased after each infiltration cycle. Equation (7) is applied between cycle 1 (reference) and the other eight cycles, obtaining an increasing trend until cycle 8 . The change pattern of the $D_{\text {RMS }}$ values is similar with the one of the tracer curve. When applying the $\mathrm{D}_{\text {RMS }}$ in the linear regression model (Equation (8)), the following equations for field and lab were obtained:

$$
\begin{aligned}
& \text { Tracer }_{\text {Field }}=0.9583-0.6084 \times \mathrm{D}_{\text {RMS Field }}+0.1270 \times \mathrm{D}_{\text {RMS Field }}^{2} \\
& \text { Tracer }_{\text {Lab }}=0.8974-0.2055 \times \mathrm{D}_{\text {RMS Lab }}+0.0144 \times \mathrm{D}_{\mathrm{RMS} \mathrm{Lab}}^{2} .
\end{aligned}
$$

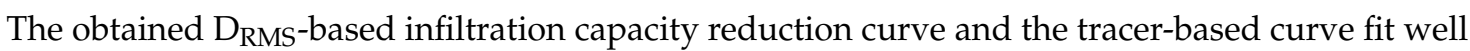
overall in the field experiment (Figure 6) with an RMSE of 0.14. In the lab experiment, the $D_{\text {RMS }}$-based value gave an abrupt sink of the infiltration capacity after the third infiltration cycle, just similar as Libardi. Therefore the RMSE between the curves raised to 0.23 .
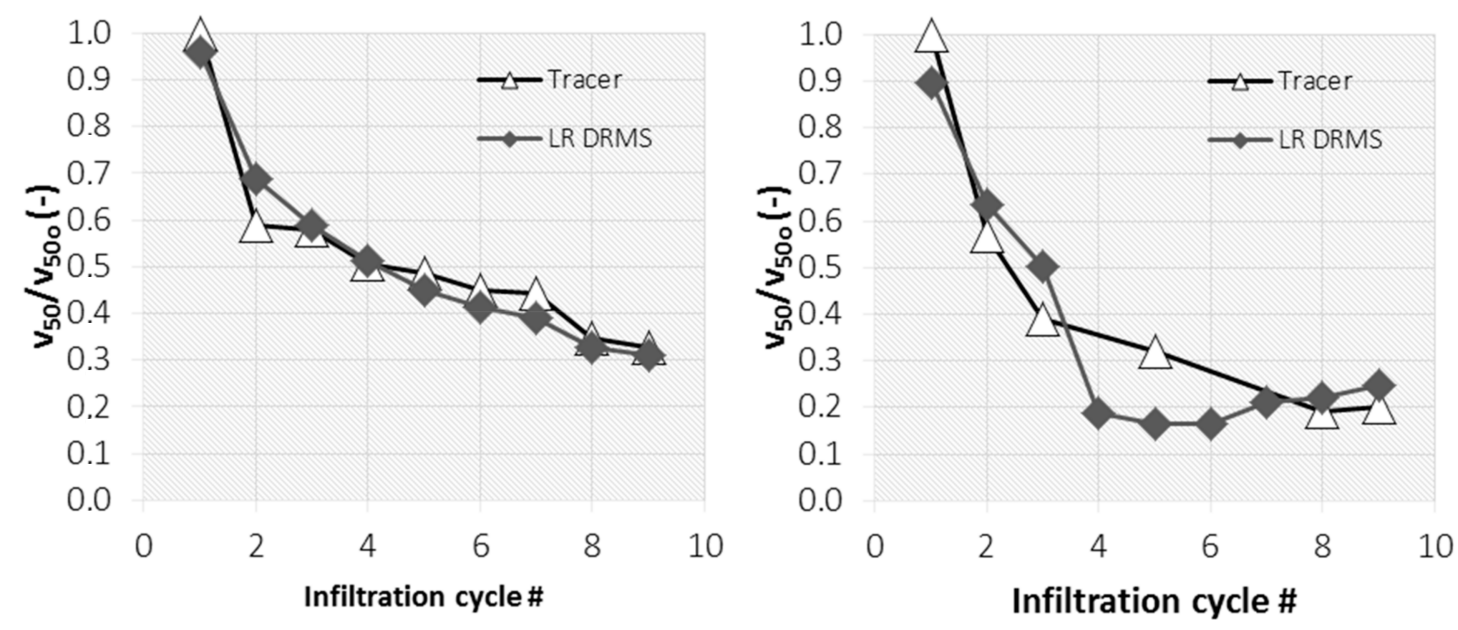

Figure 6. Comparison between tracer curve and linear regression (LR) root mean square displacement

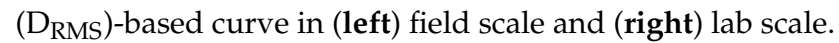

\subsection{Water Content Method}

Equation (9) allowed the determination of the tracer data using the mean water content of each infiltration cycle:

$$
\begin{gathered}
\operatorname{Tracer}_{\text {Field }}=101.3208-8.4626 \times\left[\frac{\sum W C_{i}}{n}\right]_{\text {Field }}+0.1771 \times\left[\frac{\sum W C_{i}}{n}\right]_{\text {Field }}^{2} \\
\operatorname{Tracer}_{\text {Lab }}=0.5372-0.0683 \times\left[\frac{\sum W C_{i}}{n}\right]_{\text {Lab }}+0.0029 \times\left[\frac{\sum W C_{i}}{n}\right]_{\text {Lab }}^{2} .
\end{gathered}
$$

The RMSE value between the tracer curve and linear regression water content (LR WC) curve was 0.21 in the field and 0.26 in the lab. The fit in the field was acceptable along the whole infiltration cycles (Figure 7), while in the lab the model fit better in the second half of the curve, once the steepness of infiltration capacity decrease was not high (changes below 10\%). 

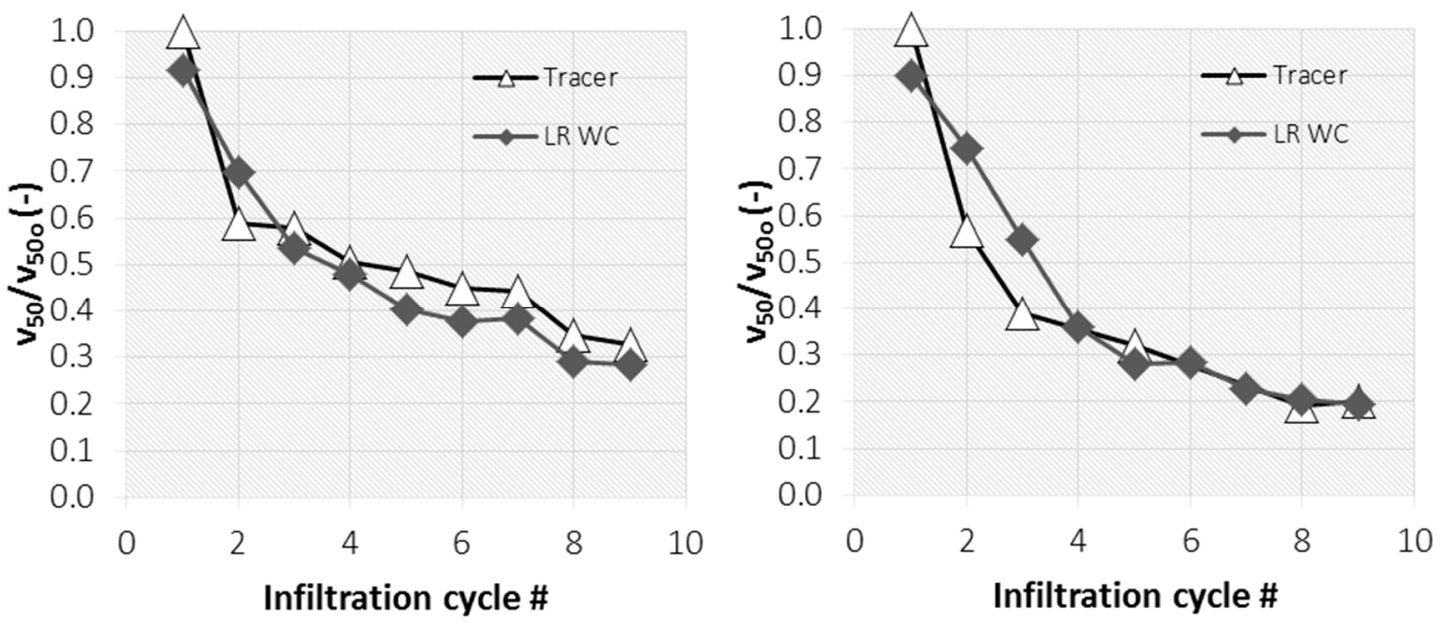

Figure 7. Comparison between tracer curve and LR water content (WC)-based curve in (left) field scale and (right) lab scale.

$\mathrm{D}_{\mathrm{RMS}}$ and water content methods represent not only the wetting process at the beginning of the infiltration (for tracer method $\sim 4 \mathrm{~h}$ ), but also include the whole $24 \mathrm{~h}$ infiltration cycle behaviour. $\mathrm{D}_{\text {RMS }}$ represents a more elaborate analysis in which data was also related in time. This may relate to the difference between both methods in the lab experiment. There was a lag phase of the water content in the infiltration cycles 4-6 that were interpreted by the $\mathrm{D}_{\mathrm{RMS}}$ method as a reduction of the infiltration capacity. The water content method sums up and averages also such differences, giving back more stable data.

\subsection{Sensor Trigger Time Method}

The linear regession model of Equation (10) was used to obtain the parameters for Equations (15) and (16) for the sensor trigger time method:

$$
\begin{aligned}
& \text { Tracer }_{\text {Field }}=2.8854-0.3112 \times \mathrm{TT}_{\text {Field }}+0.0093 \times \mathrm{TT}_{\text {Field }}^{2} \\
& \text { Tracer }_{\text {Lab }}=1.4748-0.1279 \times \mathrm{TT}_{\text {Lab }}+0.0030 \times \mathrm{TT}_{\text {Lab }}^{2} .
\end{aligned}
$$

The trigger time of the water content sensor was the best indicator to reproduce the tracer curve in the field with a RMSE of 0.06 (Figure 8); while the lab the results differred more from the tracer curve $(\mathrm{RMSE}=0.37)$.
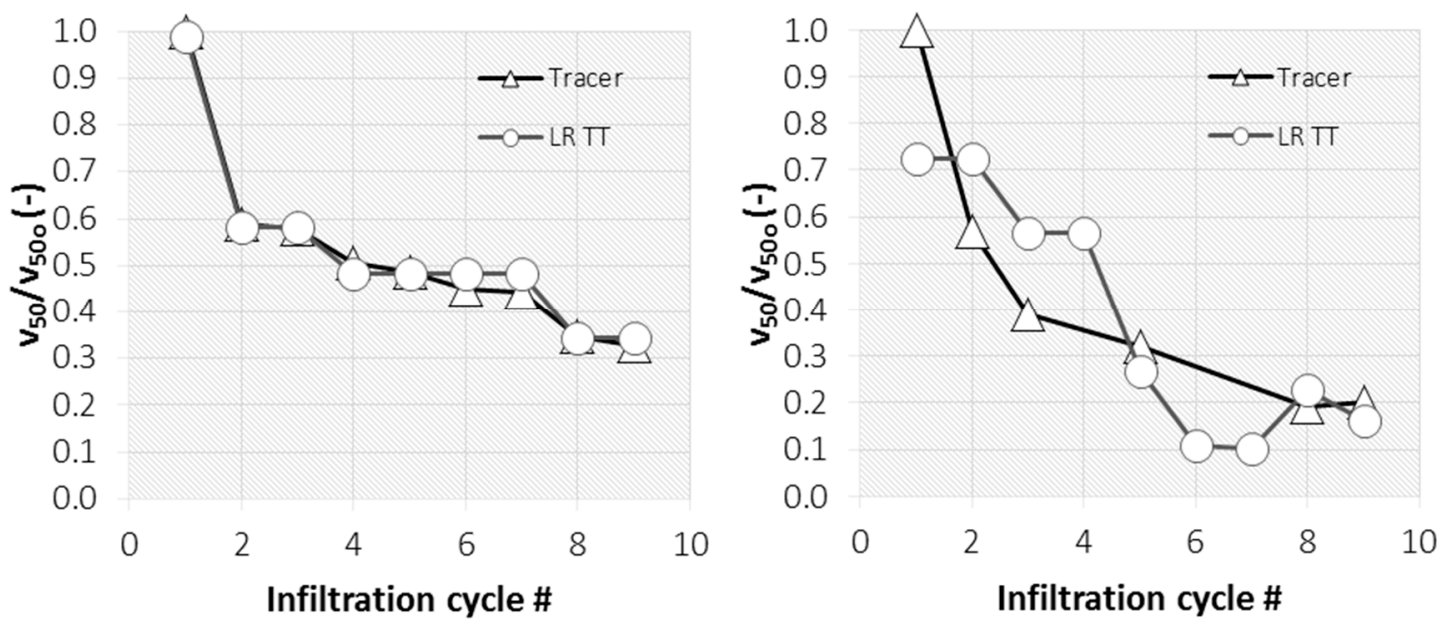

Figure 8. Comparison between tracer curve and LR trigger time (TT)-based curve in (left) field scale and (right) lab scale. 
The trigger time method produced a generally accurate estimation of the infiltration capacity reduction in the field. Nevertheless, the resolution of the measured data $(2 \mathrm{~min})$ might have been too coarse, and therefore the readings exhibited a step-shape form. Additionally, the trigger time method generated a value that was obtained only from the early stage of the infiltration cycle, similar to the tracer experiment. In the lab, the values shifted in an unpredictable manner along the tracer curve. The sidewall flow of the experiment setup may have interfered considerably with the trigger method, which is only dependant on the first change of the water content. Within proximity to the inner walls of the tank, a preferential flowpath may have resulted in the water flowing as it would do in field conditions [38].

\section{Conclusions}

The Libardi method accurately exhibited the pattern of the infiltration capacity reduction, taking into account the drying behaviour after an infiltration cycle. By increasing the number of drying periods, traceability increased with respect to the resolution of the decrease in the infiltration capacity. Sensor trigger time showed an accurate representation of the reduction in infiltration rate. Nevertheless, this was completely dependant upon the time measurement interval in which the was data stored, and represents only the conditions at the beginning of the infiltration period (similar to the tracer method). $D_{\text {RMS }}$ and water content methods were the most accurately analyzed approaches for data management in MAR basins, to determine the actual state of the infiltration capacity and additionally they calculate a value that represents the complete infiltration cycle and not just a fraction of it.

$\mathrm{D}_{\mathrm{RMS}}$, water content, and the trigger time methods all utilize linear regression models to correlates their raw data with the tracer experiments. The equations which are derived can only be used within each experiment, and in the analyzed intervals. If the boundary conditions remain the same in different experiments, the given empirical equation could also be applied.

It is worth continuing the validation of the reviewed and developed methods in different conditions in order to broaden their applications in different investigation fields by reusing the obtained linear regression equations in new experiments in the same boundary conditions, as well as by applying the methods in new scenarios with a different hydraulic loading rates.

Author Contributions: Conceptualization, F.B., T.F. and C.S.; investigation, F.B. and T.F.; methodology, F.B. and T.F.; validation, F.B. and T.F.; writing—original draft, Felix Barquero; writing-review and editing, F.B., T.F. and C.S.

Funding: This study was supported by the German Federal Ministry of Education and Research (BMBF), grant no. 01LN1311A (Junior Research Group "INOWAS").

Conflicts of Interest: The authors declare no conflict of interest. The funders had no role in the design of the study; in the collection, analyses, or interpretation of data; in the writing of the manuscript, or in the decision to publish the results.

\section{References}

1. Bekele, E.B.; Donn, M.J.; Barry, K.E.; Vanderzalm, J.L.; Kaksonen, A.H.; Puzon, G.J.; Wylie, J.; Miotlinski, K.; Cahill, K.; Walsh, T.; et al. Managed Aquifer Recharge and Recycling Options: Understanding Clogging Processes and Water Quality Impacts; Australian Water Recycling Center of Excellence: Brisbane, Australia, 2015.

2. Laws, B.V.; Dickenson, E.R.V.; Johnson, T.A.; Snyder, S.A.; Drewes, J.E. Attenuation of contaminants of emerging concern during surface-spreading aquifer recharge. Sci. Total Environ. 2011, 409, 1087-1094. [CrossRef]

3. Arshad, M.; Guillaume, J.; Ross, A. Assessing the Feasibility of Managed Aquifer Recharge for Irrigation under Uncertainty. Water 2014, 6, 2748-2769. [CrossRef]

4. Rupérez-Moreno, C.; Pérez-Sánchez, J.; Senent-Aparicio, J.; Flores-Asenjo, P.; Paz-Aparicio, C. Cost-Benefit Analysis of the Managed Aquifer Recharge System for Irrigation under Climate Change Conditions in Southern Spain. Water 2017, 9, 343. [CrossRef]

5. Dillon, P. Future management of aquifer recharge. Hydrogeol. J. 2005, 13, 313-316. [CrossRef] 
6. Bouwer, H. Issues in artificial recharge. Water Sci. Technol. 1996, 33, 381-390. [CrossRef]

7. Dutta, T.; Carles-Brangarí, A.; Fernàndez-Garcia, D.; Rubol, S.; Tirado-Conde, J.; Sanchez-Vila, X. Vadose zone oxygen $(\mathrm{O} 2)$ dynamics during drying and wetting cycles: An artificial recharge laboratory experiment. J. Hydrol. 2015, 527, 151-159. [CrossRef]

8. Sprenger, C.; Hartog, N.; Hernández, M.; Vilanova, E.; Grützmacher, G.; Scheibler, F.; Hannappel, S. Inventory of Managed Aquifer Recharge sites in Europe-Historical development, current situation and perspectives. Hydrogeol. J. 2017, 25, 1909-1922. [CrossRef]

9. Haaken, K. Applied Hydrogeophysics for Managed Aquifer Recharge; Rheinische Friedrich-Wilhelms-Universität: Bonn, Germany, 2018.

10. Council, N.R. Ground Water Recharge Using Waters of Impaired Quality; National Academy Press: Washington, DC, USA, 1969; ISBN 978-0-309-05142-2.

11. Stibinger, J.; Univerzita, J.E. Purkyně v Ústí nad Labem; Fakulta životního prostředi Examples of Determining the Hydraulic Conductivity of Soils: Theory and Applications of Selected Basic Methods: University Handbook on Soil Hydraulics; Jan Evangelista Purkyně University, Faculty of the Environment: Ústí nad Labem, Czech Republic, 2014; ISBN 978-80-7414-837-8.

12. Wagner, B.; Tarnawski, V.R.; Hennings, V.; Müller, U.; Wessolek, G.; Plagge, R. Evaluation of pedo-transfer functions for unsaturated soil hydraulic conductivity using an independent data set. Geoderma 2001, 102, 275-297. [CrossRef]

13. Bagarello, V.; Iovino, M.; Elrick, D. A simplified falling-head tecnique for rapid determination of field-saturated hydraulic conductivity. Soil Sci. Soc. Am. J. 2004, 68, 66-73.

14. Fodor, N.; Sándor, R.; Orfanus, T.; Lichner, L.; Rajkai, K. Evaluation method dependency of measured saturated hydraulic conductivity. Geoderma 2011, 165, 60-68. [CrossRef]

15. Vienken, T.; Dietrich, P. Field evaluation of methods for determining hydraulic conductivity from grain size data. J. Hydrol. 2011, 400, 58-71. [CrossRef]

16. Rosas, J.; Lopez, O.; Missimer, T.M.; Coulibaly, K.M.; Dehwah, A.H.A.; Sesler, K.; Lujan, L.R.; Mantilla, D. Determination of hydraulic conductivity from grain-size distribution for different depositional environments. Ground Water 2014, 52, 399-413. [CrossRef]

17. Askarinejad, A.; Beck, A.; Casini, F.; Springman, S.M. Unsaturated Hydraulic Conductivity of a Silty Sand with the Instantaneous Profile Method. In Proceedings of the Unsaturated Soils: Research and Applications; Mancuso, C., Jommi, C., D’Onza, F., Eds.; Springer: Berlin/Heidelberg, Germany, 2012; pp. 215-220.

18. Reichardt, K.; Portezan, O.; Libardi, P.L.; Bacchi, O.O.S.; Moraes, S.O.; Oliveira, J.C.M.; Falleiros, M.C. Critical analysis of the field determination of soil hydraulic conductivity functions using the flux-gradient approach. Soil Tillage Res. 1998, 48, 81-89. [CrossRef]

19. Fichtner, T.; Barquero, F.; Sallwey, J.; Stefan, C. Assessing Managed Aquifer Recharge Processes under Three Physical Model Concepts. Water 2019, 11, 107. [CrossRef]

20. Irving, J.; Singha, K. Stochastic inversion of tracer test and electrical geophysical data to estimate hydraulic conductivities. Water Resour. Res. 2010, 46. [CrossRef]

21. Pollock, D.; Cirpka, O.A. Fully coupled hydrogeophysical inversion of synthetic salt tracer experiments. Water Resour. Res. 2010, 46. [CrossRef]

22. U.S. EPA. The QTRACER2 Program for Tracer-Breakthrough Curve Analysis for Tracer Tests in Karstic Aquifers and Other Hydrologic Systems; National Center for Environmental Assessment-Washington Office, Office of Research and Development, U.S. Environmental Protection Agency: Washington, DC, USA, 2002.

23. Armbruster, H.; Mors, K.; Eiswirth, M.; Hoetzl, H.; Merkler, G.-P.; Naegelsbach, E. Leakage detection of sewing pipes by combined geophysical and tracer techniques. In Tracer Hydrol, Proceedings of the 6th International Syposium on Water Tracing, Karlsruhe, Germany, 21-26 September 1992; HötzL, H., Werner, A., Eds.; Balkema: Rotterdam, The Netherlands, 1992; pp. 97-99.

24. Kollmann, W.; Meyer, J.W.; Supper, R. Geoelectric surveys in determining the direction and velocity of groundwater flow using introduced salt tracer. In Tracer Hydrol, Proceedings of the 6th International Syposium on Water Tracing, Karlsruhe, Germany, 21-26 September 1992; HötzL, H., Werner, A., Eds.; Balkema: Rotterdam, The Netherlands, 1992; pp. 109-113.

25. Zellweger, G.W. Testing and comparison of four ionic tracers to measure stream flow loss by multiple tracer injection. Hydrol. Process. 1994, 8, 155-165. [CrossRef] 
26. Hoffmann, R.; Dietrich, P. Geoelektrische Messungen zur Bestimmung von Grundwasserfließrichtungen und -geschwindigkeiten. Grundwasser 2004, 9, 194-200. [CrossRef]

27. Einsiedl, F. Flow system dynamics and water storage of a fissured-porous karst aquifer characterized by artificial and environmental tracers. J. Hydrol. 2005, 312, 312-321. [CrossRef]

28. Singha, K.; Gorelick, S.M. Saline tracer visualized with three-dimensional electrical resistivity tomography: Field-scale spatial moment analysis. Water Resour. Res. 2005, 41. [CrossRef]

29. Abrantes, J.R.C.B.; Moruzzi, R.B.; Silveira, A.; de Lima, J.L.M.P. Comparison of thermal, salt and dye tracing to estimate shallow flow velocities: Novel triple-tracer approach. J. Hydrol. 2018, 557, 362-377. [CrossRef]

30. Leibundgut, C.; Maloszewski, P.; Külls, C. Tracers in Hydrology; John Wiley \& Sons: Hoboken, NJ, USA, 2011; ISBN 978-1-119-96501-5.

31. Richards, L.A. Capillary conduction of liquids through porous mediums. Physics 1931, 1, 318. [CrossRef]

32. Darcy, H. Les fontaines publiques de la ville de Dijon: Exposition et application des principes à suivre et des formules à employer dans les questions de distribution d'eau: ouvrage terminé par un appendice relatif aux fournitures d'eau de plusieurs villes au filtrage des eaux et à la fabrication des tuyaux de fonte, de plomb, de tole et de bitume; Victor Dalmont: Paris, France, 1856.

33. Buckingham, E. Studies on the Movement of Soil Moisture; US Department of Agriculture, Bureau of Soils: Washington, DC, USA, 1907; p. 38.

34. Hillel, D.; Krentos, V.D.; Stylianou, Y. Procedure and test of an internal drainage method for measuring soil hydraulic characteristics in situ. Soil Sci. 1972, 114, 395-400. [CrossRef]

35. Libardi, P.L.; Reichardt, K.; Nielsen, D.R.; Biggar, J.W. Simple field methods for estimating soil hydraulic conductivity. Soil Sci. Soc. Am. J. 1980, 44, 3-7. [CrossRef]

36. Sisson, J.B.; Ferguson, A.H.; van Genuchten, M.T. Simple Method for Predicting Drainage from Field Plots 1. Soil Sci. Soc. Am. J. 1980, 44, 1147-1152. [CrossRef]

37. Chai, T.; Draxler, R.R. Root mean square error (RMSE) or mean absolute error (MAE)?-Arguments against avoiding RMSE in the literature. Geoscientific Model Dev. 2014, 7, 1247-1250. [CrossRef]

38. Gibert, O.; Hernandez, M.; Vilanova, E.; Cornella, O. Guidelining Protocol for Soil Column Experiments Assessing Fate and Transport of Trace Organics. Available online: https://demeau-fp7.eu/sites/files/D123a\%20Guidelines\% 20Column\%20experiments.pdf (accessed on 14 February 2019).

(C) 2019 by the authors. Licensee MDPI, Basel, Switzerland. This article is an open access article distributed under the terms and conditions of the Creative Commons Attribution (CC BY) license (http://creativecommons.org/licenses/by/4.0/). 